Article

\title{
Dilemmas and Trade-Offs in Peacemaking: A Framework for Navigating Difficult Decisions
}

\author{
Anne Isabel Kraus ${ }^{1}$, Owen Frazer ${ }^{2}$, Lars Kirchhoff ${ }^{1}$, Tatiana Kyselova ${ }^{3}$, Simon J. A. Mason ${ }^{2, *}$ and \\ Julia Palmiano Federer ${ }^{4}$ \\ ${ }^{1}$ Center for Peace Mediation, Europa-Universität Viadrina, 15230 Frankfurt (Oder), Germany; \\ E-Mails: kraus@europa-uni.de (A.I.K.), Kirchhoff@europa-uni.de (L.K.) \\ 2 Center for Security Studies, ETH Zurich, 8092 Zurich, Switzerland; E-Mails: ofrazer@ethz.ch (O.F.), \\ simason@ethz.ch (S.J.A.M.) \\ ${ }^{3}$ Mediation and Dialogue Research Center, National University of Kyiv-Mohyla Academy, 04655 Kyiv, Ukraine; \\ E-Mail: t.kyselova@ukma.edu.ua \\ ${ }^{4}$ Swisspeace, University of Basel, 4001 Basel, Switzerland; E-Mail: julia.palmianofederer@swisspeace.ch \\ * Corresponding author
}

Submitted: 15 May 2019 | Accepted: 20 August 2019 | Published: 25 November 2019

\begin{abstract}
This article focuses on the dilemmas and trade-offs that third parties face when mediating violent political conflicts. Should they ignore human rights violations because pushing the issue could jeopardize relationships with political actors who grant access for humanitarian aid? Will bringing moderates and hardliners together help the peace process or radicalize moderate actors? What should dialogue facilitators do when the act of identifying non-mainstream groups to be included into dialogue increases division and polarization? The activity of peacemaking is inherently characterized by such process and strategy dilemmas where two equally compulsory imperatives seem not to be attainable at the same time. The article proposes a framework to break out of either-or thinking in these situations. We argue that: 1) making oneself aware of how a decision is perceived, and 2) systematically exploring a set of different strategies for creating new unexpected options helps to ease these decisions and avoid rotten compromises. The model reworks and combines existing problemsolving strategies to create a new explorative option generation approach to peacemaking dilemmas and trade-offs. Some of these strategies, such as sequencing and incrementalization, are already well-established in peacemaking. Others, such as compartmentalization and utilization, are rather unconsciously used. All identified strategies, however, are not yet systematically employed to manage third parties' own dilemmas and trade-offs. Under the suggested framework, these strategies can act in complement to synthesize creativity and strategic thinking with surprising ease. Using examples from the authors' peacemaking activities and observations in Myanmar, Thailand, and Ukraine, the article demonstrates the real-world benefits of the framework in terms of decision assessment and optional thinking.
\end{abstract}

\section{Keywords}

decision-making; human rights; mediation; peacemaking; peace process

\section{Issue}

This article is part of the issue "Trade-Offs in the Political Realm: How Important Are Trade-Offs in Politics?" edited by Todd Landman (University of Nottingham, UK) and Hans-Joachim Lauth (University of Wuerzburg, Germany).

(C) 2019 by the authors; licensee Cogitatio (Lisbon, Portugal). This article is licensed under a Creative Commons Attribution 4.0 International License (CC BY).

\section{Introduction}

In peacemaking, good things do not easily come together. Rather, several priorities typically compete with or con- tradict one another. As both scholars and practitioners of this field, working in Myanmar, South Thailand, and Ukraine, we see firsthand the dilemmas inherent in peacemaking processes, and also the sacrifices in the 
trade-offs we and others make in these situations. In essence, even the most basic principle of 'do no harm' is sometimes arguably unachievable (UK Government Stabilization Unit, 2019, p. 7). Thinking how we-and others in the field-could better deal with these quandaries, we delved into the problem-solving and decisionmaking literature of various disciplines and found a range of promising strategies for dilemma and trade-off situations. Through an iterative process we developed the Tough Choices Framework. The prototype has been roadtested and adapted in a first round of practical applications. In this article, we share this model for the first time with the wider public. More broadly, we aim to create an understanding of dilemmas and trade-offs as inherent tensions of the peacemaking process, which require responses based in sensitivity, creativity and pragmatism.

Our understanding of peacemaking encompasses all third-party interventions that aim to prevent, manage or resolve violent conflicts. The dilemmas and trade-offs in this field are as manifold as the contexts and situations in which they occur; yet they all reflect peacemaking's basic dialectics between negative and positive peace, short and long-term goals, and pragmatic and ethical or legal aims: "First, the third parties must help the belligerents abandon the status quo of armed hostilities. Second, they must foster a new relationship between the combatants that precludes the return to violence" (Beardsley, 2011, p. 3). Particularly when tempted or pressured to settle agreements quickly (UN, 2006, p. 495), the resulting compromises can have significant negative societal impacts, such as "sacrificing democracy in the short-run in order to establish peace and stability as pre-requisites for the consolidation of democracy in the long-run" (Nathan, 2016, p. 3). In essence, peacemaking dilemmas and trade-offs result from the apparently competing mandates that pervade the whole field, with roots in the UN Charter and other key documents (e.g., 'stop the fighting' and 'address punishable human rights violations,' UN, 2006, p. 495).

Despite a growing range of studies that focus on peacemaking dilemmas of political and strategic (Beardsley, 2011; Greig \& Diehl, 2005; Margalit, 2010; UK Government Stabilization Unit, 2019, p. 5; Zartman, 2008), methodological, ethical, and legal nature (Bush, 1994; Frazer, 2015; Hellmüller, Palmiano Federer, \& Pring, 2017; Kraus, 2011a, 2011b; Palmiano Federer, 2018; Shapira, 2018, pp. 354-363), their generic patterns and mitigation techniques have not yet been systematically analyzed in the conflict resolution literature. Only the brokering of agreements that may violate international norms has gained some attention, for instance in the context of transitional justice (Davis, 2014; Hayner, 2018; Kirchhoff, 2009), gender equality or inclusivity (Lanz, 2011; Paffenholz, 2014). Single studies encourage mediators to apply mediation techniques to their own dilemmas (treating conflicting imperatives as positions and underlying goals as interests) but again leave open how to deal with conflicts between incommensurable goals
(Shapira, 2018, p. 361). Hands-on guidance for peacemakers on how to manage dilemmas and trade-offs in everyday practice is particularly rare (UK Government Stabilization Unit, 2019). Altogether, there is a remarkable discrepancy between the level of difficulty and magnitude of sacrifices resulting from dilemmas and tradeoffs in peacemaking, and the low awareness and scant methodological resources to address them.

Conversely, other disciplines like psychology, ethics, and business, offer a broad range of methodologies for dealing with dilemmas and trade-offs in a constructive manner (laid out in Sections 3 and 4). Their common denominator is that even in the most controversial, deadlocked and painful cases, there are more unexpected possibilities than usually imagined. To detect these possibilities, one needs to employ exploratory optional thinking, i.e., systematically develop multiple and diverse options without seeking confirmation for what is already seen as (not) viable (Schneider \& Shanteau, 2003, pp. 438-439; Weston, 2006, pp. VI, 3, 7). Most peacemaking actors are familiar with such techniques to find common ground between conflict parties (Cooley, 2005), but they usually do not apply these skills to their own dilemma perception and decision-making. Nor are these techniques alone enough. They need to be integrated into an approach that expressly helps to break out of habitual patterns of thinking.

We argue that truly constructive ways of dealing with dilemmas and trade-offs begin when we acknowledge that we have reached an impasse and look beyond the immediate controversies and difficulties, and beyond what we hold as right and wrong (Weston, 2006, p. VI). This means deliberately changing our mode of thinking: abandoning the unfruitful efforts of forcing the competing claims together, and instead exploring unusual and more indirect responses in a creative and playful manner. We are not arguing for discarding the standard response of deliberating and weighing the conflicting imperatives (Shapira, 2018, pp. 357-360), but rather for complementing this practice with a preceding routine: respect normative, political and practical limits where they have a truly constitutive function, try to deconstruct them where they do not, and uncover and utilize the space of unusual but acceptable possibilities that have either been overlooked or never explored.

The model we developed emerged from bridging dilemma theory and peacemaking practice using an action research approach (Kraus \& Kyselova, 2018). Theoretical and methodological knowledge was applied to, and tested in, peacemaking activities, and from that a framework was developed that aims to be helpful both in theory and practice. The modeling was inspired by bricolage research (Rogers, 2012), meaning that we assembled different conceptual and methodological approaches to get a better grasp of the problem so as to develop alternative readings and practices (Rogers, 2012, pp. 1-2). The model re-contextualizes existing decision-making concepts as well as problem-solving and 
dilemma strategies and marries them into a new overall approach. The prototype will be further tested and modified in collaboration with practitioners and political decision-makers until it has proven useful in different peacemaking contexts.

After briefly outlining three examples that will serve as illustrations throughout our article, we then clarify what precisely makes those decisions difficult from a conceptual point of view. Next, we describe the ideas that inspired the model, explain its components and demonstrate how it works.

\section{Difficult Decisions in Peacemaking: Three Examples from Myanmar, Thailand, and Ukraine}

The three examples that illustrate the type of difficult decisions on which we are focusing draw on our own experiences and observations in Myanmar, Thailand, and Ukraine. These cases were selected both for pragmatic and methodological reasons. Given that we were directly involved in supporting or observing peacemaking activities, these contexts were a natural place to begin our investigation. Methodologically, they also represented diverse settings, with differing intervention strategies, which could be compared and contrasted to build a generalizable framework.

\subsection{Myanmar}

In 2017, attacks by the Arakan Rohingya Salvation Army on government outposts in Myanmar's northwestern Rakhine state resulted in the Myanmar military's disproportionate crackdown on the Rohingya Muslim population. The crackdown has led to mass exodus of more than 700,000 Rohingyas into neighboring Bangladesh (Human Rights Council, 2018). For the UN in Myanmar, two imperatives clashed: On the one hand, the UN mandate clearly called for a response to grave human rights abuses against the Rohingya population. On the other hand, it was necessary for the UN to maintain a cooperative relationship with the Myanmar government and military in order to ensure the provision of aid to both Buddhist Rakhine and Muslim communities in Rakhine state. The UN's normative imperative to uphold and protect human rights thus collided with the strategic and normative imperative to maintain political, humanitarian, and developmental access to the country.

\subsection{Thailand}

A violent separatist conflict in the Malay Muslim majority south of Thailand has claimed over 6,000 lives since 2004. Many in the minority Buddhist community feel marginalized, perceiving that peacebuilding efforts there have focused on the grievances of the Malay Muslim population. An intra-Buddhist dialogue project was launched to prevent such sentiments from becoming an obstacle to peacebuilding. The project aimed to: a) provide a safe space for Buddhists to voice their concerns; b) support Buddhists to communicate these concerns to other stakeholders; and c) thereby encourage efforts by the authorities and Malay Muslims to engage with the Buddhist community in a way that took account of their concerns. However, facilitating a dialogue inclusive of all viewpoints within the Buddhist community risked providing a platform for 'anti-peace' voices interested in strengthening opposition to engagement and dialogue with other groups. Thus, the project's approach of preparing the Buddhist community to engage with other stakeholders in constructive ways that could contribute to peacebuilding ran the danger of undermining the support for Buddhist involvement in peacebuilding that it ultimately aimed to promote.

\subsection{Ukraine}

Currently, inter-community dialogues in Ukraine suffer from the absence of Ukrainians with non-mainstream political views such as anti-Maidan, anti-European, or proRussian (Kyselova, 2018). These views are widespread enough to deserve a voice (SCORE, 2016) and according to the basic assumption of the inclusion imperative, any societal model that does not include them will be inherently undermined. Within the adverse context of on-going armed conflict in the East of Ukraine and the dominant conflict narrative of Russian aggression in Ukraine, these population groups are dispersed, disorganized, and delegitimized by dominant political discourse. To include them, one would first need to identify and legitimize them. However, beyond the security risks of such inclusion, dialogue facilitators fear that by naming and distinguishing these political identities they would strengthen or even initiate dynamics that would inevitably deepen the division lines in the society, namely in-group/out-group identity narratives and polarizing political identity discourses in the public sphere (Svensson \& Brounéus, 2013).

\section{Dilemmas and Trade-Offs: What Makes Them Difficult-And Easier}

Dilemmas and trade-offs are closely related terms. As decision-making and conflict resolution literature offers no precise distinction so far (definitions rather seem to overlap, see Gowans, 1987, p. 3; Shapira, 2018, p. 354), we suggest the following delineation of the terms.

We understand a dilemma as a standoff between two or more imperatives (A vs. B) that are perceived as equally compulsory but not attainable at the same time, leaving only either-or options. A trade-off is understood as a balancing of two or more imperatives ( $A$ vs. B) that are perceived as similarly compulsory and opposed, but partly satisfiable at the same time by exchanging one thing in return for another. Both, dilemma and trade-off, can arise from normative and pragmatic claims. The distinction between the terms lies in two aspects: a) the 
state of perceived solvability-in a dilemma there seem to be only clearly exclusive solutions possible that either way neglect one of the imperatives, while a trade-off represents a balanced solution between both imperatives; b) the state and moment in time of the decision-making process - a dilemma is an unsolved decision problem where no decision could be made yet, while a trade-off represents an act or a result of a weighing up, thus a solved decision problem, even if this solution is not satisfying. The also closely related term of a paradox, which is often confused with the term of a dilemma, describes one self-contradictory statement, whereas a dilemma and a trade-off both result from two contradictory, or mutually exclusive, claims.

Using these terms as analytical lenses for the examples outlined above, the inter-community dialogues in Ukraine are hampered by what we, as observers, perceive as a dilemma: The imperative to include all relevant political groups in political discourse $(A)$ clashes with the equally essential imperative to prevent further polarization within Ukrainian society (B). In the somewhat similar situation in southern Thailand, facilitators perceived the two opposing imperatives rather as a trade-off that had to be made: Giving space to the 'anti-peace' voices (A) had to be constantly balanced with the other central imperative, which was to jointly develop 'pro-peace' ideas and actions within the Buddhist community (B).

Holding a cognitive constructivist point of view, we consider dilemmas and trade-offs as perception patterns created by reference frames such as ideas, practices, narratives, goals, values, emotions, and beliefs (Goffman, 1986; Lakoff \& Wehling, 2016). Frames are key codes for making sense of the world and thus tend to resist change; when their premises are incommensurable, compete, or collide, a dilemma or trade-off is the result. Like the frames themselves, the perception patterns of dilemmas are contingent: Some people see dilemmas and trade-offs where others-with other contexts and histories-do not (Acharya, 2004; Harding, 2017). However, as frames are inextricably linked to unconscious thinking habits, worldviews, existential experiences, and social identity, they can be difficult to modify. Cognitive mechanisms like confirmation bias, where contradictory information is filtered out, also serve to reinforce existing reference frames that underly one's original assessments of a situation.

The less constitutive a reference frame is for the individual or social system holding it, the easier it is to alter it and consequently what constitutes a dilemma or tradeoff. Fundamental normative convictions and established principles will remain unsusceptible to such deconstruction, but they might entail more flexible aspects than assumed. For instance, if the frames that determine what ought to be done resist any attempts to change them, the frames determining how this ought to be done might be more open and flexible. Weston (2006, pp. 36-37) gives some examples from other contexts for generating options that vary the how without disregarding given limits of the what: The owner of a cafeteria in the 1950s in
North Carolina removed all tables from the place to treat white customers the same way as black customers who were forbidden to sit down under segregation-era laws. Instead of seating black customers in direct defiance of the law he looked for other modes of opposition; thus, the first stand-up café was born of an anti-apartheid initiative. Another example is the teacher who shaved her head after a child who had lost her hair in chemotherapy was laughed at by classmates, resulting in a rash of children also begging their parents to cut their hair. Instead of camouflaging or moralizing the problem, the teacher responded indirectly through an act of solidarity, which turned an odd action into an appealing one (Weston, 2006, pp. 36-37):

The general rule is to revisit all the parts of a problem, not just the one or two that currently fill the screen....It may well be that some other aspect of a problematic situation, pushed into the background at the moment, offers us a way to go forward while the current routes seem blocked.

This suggests we do not need to seek for better ways to unblock blocked cognitive routes (embedded reference frames that are resistant to change) but search for better ways to detect and utilize flexibility in other aspects of a dilemma or trade-off (reference frames that leave more space for solutions than assumed).

In order to develop useful, applicable guidance for decision-makers, our conceptual approach deliberately focuses on the decision-makers' subjective contextual and situational perception when facing a decision. Theoretical concerns, like the validity and even existence of logical dilemmas (Gowans, 1987, pp. 3-33; Statman, 1995, pp. 29-54), will be left aside, as they are irrelevant from a practitioner point of view: Whether or not the dilemma is logically real or only perceived, in any case the decision-maker will have to explore the extent to which it can be effectively deconstructed in the (inter)subjective reality of those involved.

\section{The Tough Choices Framework: How to Make Difficult Decisions Easier}

\subsection{Requirements}

Dilemmas and trade-offs force peacemakers to make decisions under highly challenging conditions: A problem's complexity is often exacerbated by a lack of information and predictability regarding the potential costs and benefits of different solution options. Furthermore, the humanitarian, societal, political, moral, and monetary costs deriving from a proposed decision might be impossible to prioritize.

However, extensive needs assessment with practitioners revealed that, rather than a complex instrument for calculating and weighing up of potential costs and benefits of available options, what is required is a sim- 
ple framework for exploring whether better options exist(ed) than the ones already adopted. We explain this by drawing on dual process theories of decision making: The actual weighing up of costs and benefits takes place in the automatic, intuitive thinking of system 1 , in which an experienced practitioner can correlate numerous sets of subtle data from comparable cases, faster and more reliably than any artificial intelligence can, let alone any model we would be able to develop. In contrast, for generating new options that actually could expand the benefits and reduce the costs, pro-active efforts of the systematic, rational, self-reflective thinking of system 2 are required (Kahneman, 2012; see also Section 4.3). System 2 thinking needs both more time and consciously structured guidance in order to produce meaningful results.

With this working hypothesis on the requirements for the model we focused on strategies for generating new options in a systematic fashion to support system 2 thinking, while system 1 thinking would automatically digest and weigh up the results. We still included routine feedback loops for assessing the degree of satisfaction achieved through the strategies, but the actual weighing up of benefits and costs is deliberately left to system 1 thinking. In our future research, we will test the hypothesis behind this set up; in case it proves wrong, an element for systematically weighing up the costs and benefits of the options generated by the strategies needs to be integrated into the model.

\subsection{Theoretical Underpinnings}

This section presents a short overview of the main theories that inspired the framework.

An important indicator that reflective practice is needed is when "professionally designed solutions to public problems have had unanticipated consequences, sometimes worse than the problems they were designed to solve," as seems to have been the case in some peacemaking compromises (Schön, 1983, p. 4). Reflective practice models are simple, cyclical structures for problem assessment, developing options, and planning implemen- tation (see Borton, 1970). Some of these models have already been applied to mediation (Macfarlane, 2002). With adaptive peacebuilding (de Coning, 2018), iterative experiential learning has become an important aspect of improving peace processes on the whole, but it has not yet been applied to dealing with dilemmas.

In complex or chaotic environments such as peacemaking, where no clear cause-effect relationships are discernible and contexts vary greatly, a decontextualized best practice from one context will not work in most other cases (Mason, 2016; Snowden \& Boone, 2007). Thus, the best way to find out what works in a conflict scenario is by experimenting with different strategies. As a result, any generic model for peacemaking dilemmas and trade-offs must avoid rigid, reductive, mechanistic thinking, and offer diverse and flexible options for promoting exploratory thinking.

Drawing on cognitive dual-process theories, we hold that whenever decisions imply a high degree of complexity or create cognitive dissonance (Festinger, 2009), they require both intuitive system 1 and systematic/deliberative system 2 thinking to ensure the most optimal solution (Gigerenzer, 2008; Kahneman, 2012). Particularly where a decision-maker can draw on internalized experiential knowledge in their own judgments, deliberative routines should be combined with intuitive ones. Therefore, we aimed at a decision-making model that would activate both analytical and creative thinking in concert.

\subsection{Main Components}

The framework consists of a three-component model focusing on clarifying the decision situation and stimulating creative exploratory thinking. It offers two types of strategies to generate innovative and unexplored options: 'Separating the Responses,' and 'Reframing the Reference Frames' (Figure 1).

The strategies can be attempted in any sequence until the potential solutions are considered sufficiently satisfying to all actors concerned. The principle of 'Starting

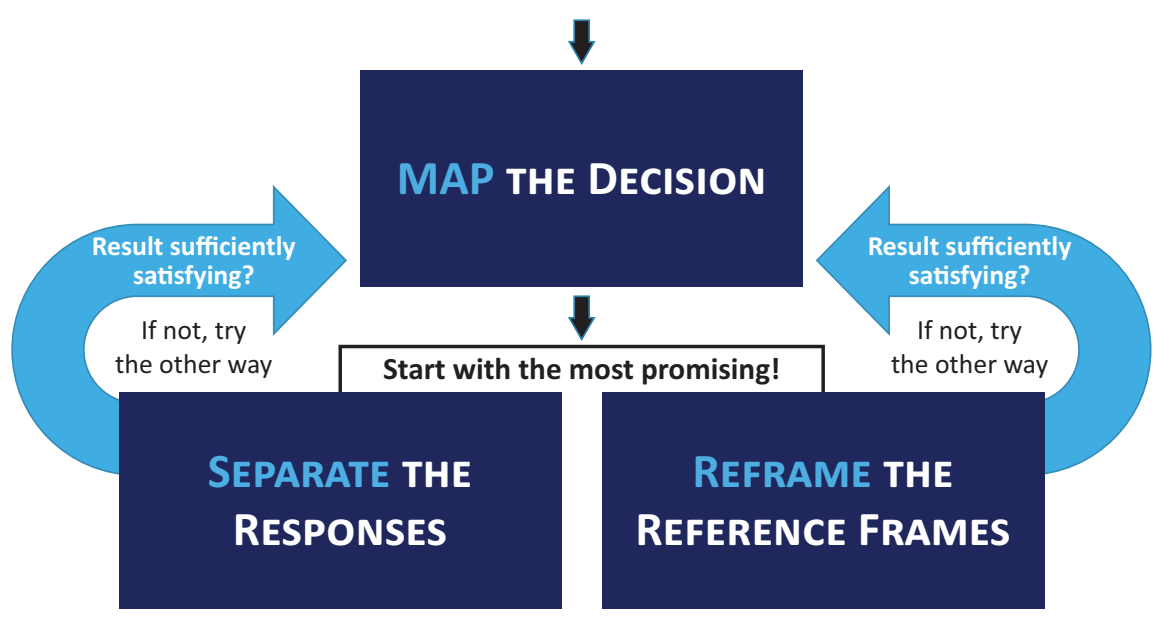

Figure 1. Main components of the Tough Choices Framework. 
with the Most Promising' hence refers to the choice of strategy for generating new options, not to the choice between the conflicting imperatives. Thus, it is an instrument for enlarging the bunch of options before or while processing the weighing up in the highly complex and efficient manner of system 1 thinking (see Section 4.1).

This also implies that the prototype model leaves also the identification of biases and blind spots (e.g., costs for indirectly affected actors) and the explicit balancing of risks to the individual decision-maker. Methodical guidance for opening the entrapped or resigned mind to truly new perspectives and ideas seemed (at least at this point of research) much more important than ethical guidance preventing and correcting shortcomings and distortions when considering benefits and costs. We assume that peacemaking actors do see the costs and risks of their decisions and are constantly balancing their competing priorities; what they lack are the methods to decrease these potential costs in the first place. In the next round of testing the model in practice, we will check if this assumption holds true.

\subsection{The Framework}

\subsubsection{Analyze the Decision Situation}

The first step is mapping how the decision situation is perceived by answering the following questions: What are the conflicting imperatives (A vs. B)? Are we facing a full dilemma or trying to balance a trade-off? What reference frames within the conflict, process and third-party system exacerbate this tension?

In reference to the second question, the literature offers no integrated analytical instrument to assess how a decision problem is perceived. We propose the following map: juxtaposing two factors, the (non)negotiability of imperatives and the (in)compatibility of responses, de- termines the perception of difficult decision situations. These factors can then be used to interrogate this perception and demonstrate how it might be altered to find more satisfying solutions. Figure 2 measures the negotiability of imperatives on the vertical axis, and the compatibility of responses on the horizontal axis. The point where the two axes converge marks the lowest degree of solvability and the diagonal opposite side marks the highest. The resulting map measures the distance to a satisfying solution for a given difficult situation.

Dilemma and trade-off situations have in common that responses seem mutually exclusive or incompatible. They differ in the degree of negotiability of their imperatives: In a dilemma, the imperatives are perceived as non-negotiable, leaving only either-or options. In a tradeoff, a compromise that balances the two imperatives is at least potentially achievable.

In the field of human rights, Margalit (2010) coined the term of 'rotten compromises' for unacceptable solutions, referring to the appeasement politics vis-à-vis the German Nazi regime as an example: rotten compromises "are not allowed, even for the sake of peace" because they "establish or maintain an inhuman regime, a regime of cruelty and humiliation, that is, a regime that does not treat humans as humans" (Margalit, 2010, pp. 1-2). On the map, rotten compromises are to be located opposite to trade-offs: There is a practically feasible way out of a dilemma but at the cost of something non-negotiable. By integrating this term, it is possible to distinguish between acceptable (trade-offs) and unacceptable (rotten) compromises. Dilemmas, trade-offs, and rotten compromises all induce a distributive lose-lose or win-lose perception pattern; win-win seems to be unthinkable in all situations (Spangler, 2013).

The concepts of dilemma, trade-off, and rotten compromise should be illustrated with the example from Myanmar. As introduced above, for the UN in Myanmar,

\section{?}

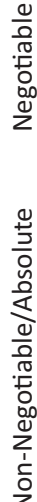
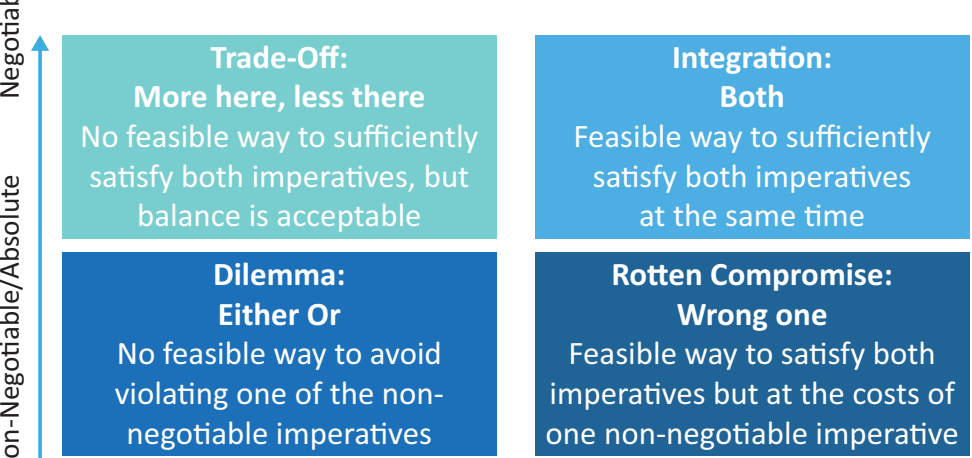

Rotten Compromise:

Wrong one

Feasible way to satisfy both

imperatives but at the costs of

one non-negotiable imperative

Incompatible/Mutually Exclusive

\section{Practical Compatibility of Responses}

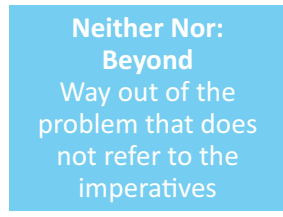$$
\text { imperatives }
$$

Figure 2. Anatomy of difficult decisions. 
two imperatives were involved: responding to (and maybe preventing further) grave human rights abuses against the Rohingya minority $(A)$ and maintaining a cooperative relationship with the Myanmar government and military in order to ensure the provision of aid to both Rakhine and Rohingya communities in Rakhine state (B). One possible perception of this situation is to regard it as a dilemma that leaves no other choice than to either prioritize humanitarian access or publicly criticize human rights violations. Another possible perception is to see the situation rather as a trade-off than a complete dilemma, for example, consider it an acceptable compromise to respond to the human rights imperative by making non-public representations to the government. However, for many international observerswithout insight into internal decision-making processes and parameters-such a response focusing on the humanitarian could easily be perceived as a rotten compromise, compromising too much on human rights for short-term humanitarian access (Safi, 2018). The frames complicating the situation were substantial international pressure to address human rights (without understanding the nuances of the context), a perception by many national actors of UN activities as foreign intrusion, and probably also a lack of a clear and coherent mandate from UN headquarters and UN member states.

The map suggests two further alternative decision situations that do not entail compromising on imperatives. The term 'integration' refers to situations where a winwin response is possible that gives both claims what they want to an sufficient extent; it represents a compatibility and negotiability of the responses (Sparrer, 2007, p. 106; Statman, 1995, p. 8). A neither-nor situation avoids the typical patterns of either-or thinking, as it does not respond to the imperatives at all but is capable of transcending them (through humor or refraining from evaluation, for example; Sparrer, 2007, pp. 106-108). In the Myanmar case, an integrative solution of the UN could be to delegate the provision of humanitarian aid to another organization making sure that the humanitarian imperative is fully taken care of by somebody else, so the UN can focus its mission on human rights issues. Here, an integration of imperatives is made possible by thinking beyond the actors and resources already considered for response. A neither-nor situation would entail the promotion and acceptance of a Myanmar national identity that recognizes and accepts diverse ethnic and religious backgrounds, so that conflicting ethnoreligious groups may co-exist together without feeling a sense of loss or concession. This would require, however, inter-generational change of historical narratives, thus identity reference frames embedded over hundreds of years, and is far beyond the scope of many international peace supporters, including the UN.

As one navigates through a decision-making process and considers different response options, one's perception of a situation may move between the different positions on the map: For instance, one might start from a dilemma perception and see no viable options at all; then, trying out all of the strategies, one might find the resulting options represent a rotten compromise, or a trade-off, or even the possibility for an integration of both imperatives or a neither-nor solution. The model's dilemma strategies will thus be mainly used to reconfigure dilemma, rotten compromise, and trade-off positions into a somehow better position, ideally into an integration or neither-nor configuration.

Locating their own perception of the decision problem on the decision map can help peacemakers to visualize how the other positions would look like in their case. This brings their thinking closer to the next step, to search for strategies that avoid unacceptable and unnecessary compromises on imperatives. In the following section, we outline a menu of response options that peacemakers can consider to this effect.

\subsubsection{Developing Response Options}

Once the situation has been mapped, the next step of the framework is to choose from two sets of strategies for developing response options (Figure 3 ). The strategies offer different avenues to address the perception of difficulty of a given decision that was analyzed in step one: 'Separating the Responses' aims to deconstruct the incompatibility of response options to conflicting imperatives. 'Reframing the Reference Frames' seeks to deal constructively with the non-negotiability of imperatives. The two avenues help assess what type of strategy might be fruitful: Is the case so intractable because the responses to the two imperatives are so incompatible that they can simply not be realized at the same time? Then one might first try the strategies in the first column that in one way or another hold the conflicting responses apart. Or is the situation so difficult because the two conflicting imperatives are so absolute that that they cannot be reconciled? In this case one might first try the strategies in the second column that address flexible elements in the framing of the whole problem perception or in how acceptable responses can look.

In working through the strategies, the most organic approach is to start with the set of strategies that, according to this first assessment of the case, looks most promising. Then one may continue in any sequence in an explorative way. It is recommended that all four strategies in a set are applied to ensure as robust a solution as possible is found. The specific case conditions that make one or the other strategy appropriate to particular decision problem types will be explored in further comparative empirical research using this prototype as a common basis. As well, we will investigate whether the strategies typically produce specific types of results (rotten compromises, trade-offs, integration, neither-nor).

While brainstorming potential solutions, an intuitive process of balancing and evaluating priorities automatically takes place (see Sections 4.1 and 4.2). Not all strategies will make sense in each case, and some might even 


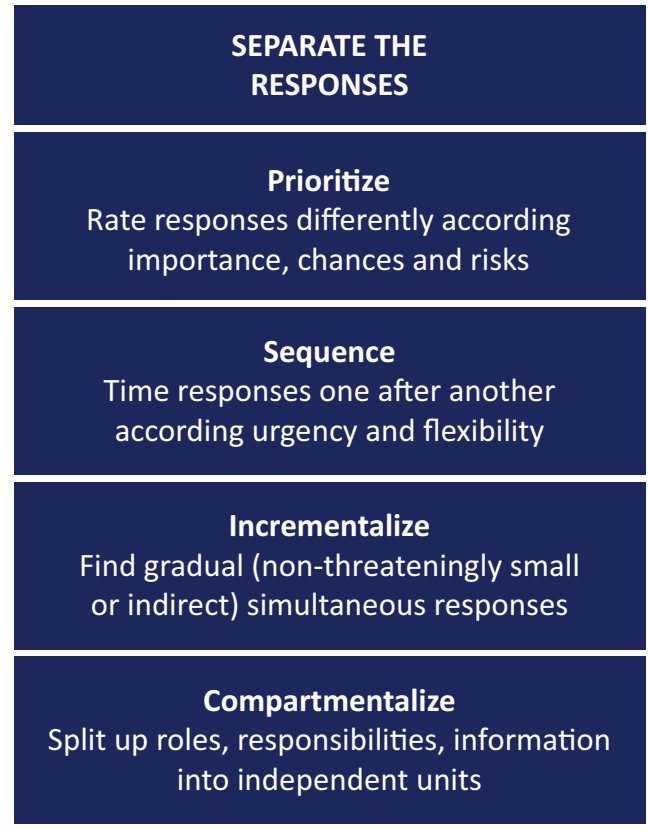

Figure 3. Strategies for developing options.

do harm in certain circumstances. Therefore, it is vital that, in addition to this automatic evaluation process, all potential solutions be located on the decision map so their degree of success can be measured (Figure 1).

\subsubsection{Strategies to Separate the Responses}

The approach of the four strategies in this column is to uncouple the responses from the conflicting imperatives: They challenge the perceived necessity to respond with the same importance (Prioritize), at the same time (Sequence), to the same extent (Incrementalize), or by the same actor (Compartmentalize).

Prioritizing, the most classical strategy in all fields from management to ethical decision-making, is ordering the responses according to their importance, urgency, opportunities, and risks, or effort required (Gert, 2007, pp. 60-79). However, ranking is only possible if one overriding frame (e.g., ethical ideals, political or practical necessities) can be established. In dilemmas with competing, incommensurable reference frames prioritization is unlikely to bear fruit. With regards to the Rohingya crisis in Myanmar, the UN seemed to have prioritized the imperative to keep life-saving humanitarian access to all residents in the poverty-stricken Rakhine state over the imperative of explicitly addressing deep-seated political and human rights abuses reported against Rohingya Muslims (which held comparably low chances of success).

Sequencing, another well-established strategy in peacemaking (Weiss, 2003), refers to timing responses one after another according to their urgency and flexibility. The typical risk of this strategy-failing to envision follow-up steps or getting derailed after the first step(s) are completed-needs to be carefully managed. In the case of Thailand, the trade-off between 'anti' vs.
REFRAME THE REFERENCE FRAMES

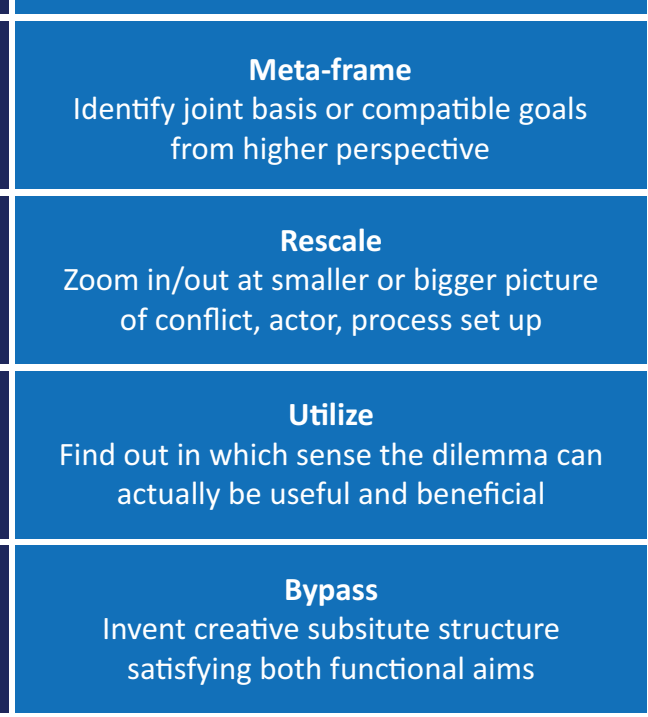

'pro-peace' voices was balanced out by sequencing them: First giving space to 'anti-peace' voices, based on the assumption that they needed to feel heard before they could listen and be ready to change their attitudes towards peacebuilding activities. In Ukraine, the current absence of pro-Russian groups from dialogue activities can be rationalized as postponing the inclusion of these groups until the hot phase of the armed conflict is over. This might explain why around $70 \%$ of the dialogues carried out by professional local Ukrainian facilitators deal with technical issues (reforms, Human Rights, integration of IDPs, restoration of community infrastructure), but not with reconciliation (Kyselova, 2018).

Incrementalizing is an increasingly popular approach in the peacemaking field (Conciliation Resources, 2018; Hayes, 2017), but has yet to be explicitly incorporated in dilemma/trade-off strategy. It describes a gradual accumulation of small or indirect changes in service of an imperative that are compatible with responses to a conflicting imperative. The imperceptibility of changes reduces resistance to these interventions and lets the system slowly adapt to change. Because of the ethical dangers of imperceptible manipulation, incremental strategies need to be critically examined to confirm whether they are justified and must ensure the consent of actors for the intended changes. The Thailand dialogue project incrementally shifted the exclusive focus on intragroup dialogue (which risked reinforcing or perpetuating anti-peace voices) to a mix of intra-group dialogue and inter-group dialogue with representatives of Malay Muslims. Hardliners could become more familiar with Malay Muslims and come to see the value of rebuilding relationships.

Compartmentalization, a concept taken from psychoanalysis, describes mechanisms that permit contra- 
dicting cognitions, principles, tasks, or responsibilities to co-exist without friction by setting boundaries between them or splitting them up in independent units (McWilliams, 2011, pp. 135-136). In political science, organization theory, and economics, compartmentalization underpins the idea of role division, delegation, and outsourcing (Falcó-Gimeno, 2011). In its most radical form, mediation actors with non-negotiable conditions or restrictions might be replaced by other more flexible ones. In the years before the crisis, there seemed to be a role division between different UN actors, with UN actors with specific human rights or humanitarian mandates being delegated to carry out substantive negotiations on human rights and humanitarian issues. However, as some Myanmar nationals in Rakhine state see all international actors as a monolith, many stakeholders still viewed the UN in Myanmar as a human rights agent. Perhaps this could have been overcome by shifting certain activities, e.g., provision of humanitarian aid, to organizations outside the UN system, leaving the UN to focus on human rights issues. In Thailand, compartmentalization could be used in targeted dialogues with sub-groups (e.g., only monks or hardliners) as small group dialogue is more transformative than larger group dialogue with higher diversity.

\subsubsection{Strategies for Reframing the Reference Frames}

The approach of the second set of strategies is to identify alternative reference frames that allow for the issue to be seen as a creative opportunity (Goffman, 1986; Weston, 2006). To achieve this, one can identify commonalities (Metaframe), focus or broaden perspectives (Rescale), find hidden opportunities (Utilize) or develop acceptable substitutes (Bypass).

Metaframing looks at conflicting imperatives from a broader perspective to find a joint basis or goal. In peacebuilding, metaframing is already successfully used to bridge divided groups by strengthening overarching common identities (Sasse \& Lackner, 2018; Shapiro, 2017). For example, in Northern Ireland efforts have been made to bridge the divide between Catholic/Nationalist and Protestant/Unionist identities by emphasizing a common Northern Irish identity. Similarly, technical dialogues in Ukraine already frame discussions around broad issues of practical concern to all that encompass the specific issues of many groups (Kyselova, 2018, p. 9). Frames such as talking about shortcomings of political reforms might be also able to attract unrepresented political views without dividing the participants along political lines.

Rescaling zooms in or out to a smaller or bigger picture of the conflict, the process and the third-party context. This practice can allow a switch into a genuinely different process logic, with different premises and goals. In this case, the Ukrainian example may once again be instructive. Including and validating pro-Russian perspectives in a country that largely considers Russia as an aggressor might be an unrealistic task. Comparatively, in- corporating these minority viewpoints at the local level, and focused on specific and concrete themes (e.g., decommunization) may prove more feasible. In Myanmar, the situation in Rakhine state could be rescaled from either human rights or humanitarian access imperatives to larger political themes such as national identity and belonging, the legal and constitutional framework, the role of authority, self-determination, equality, and education.

Utilization, a strategy derived from psychotherapy (Hammel, 2011), turns the problem into a resource: It explicitly recognizes and positively takes advantage of controversial elements instead of fighting against them. The unexpected, and often openly paradox positive framing of an acknowledged obstacle can result in a moment of enlightened surprise, and thereby a release of pressure. In the Thai case, a fearless acknowledgement of the fear of radicalization could give the groups an opening to discuss their differences and shared views without constraints-perhaps blowing off the elephant in the room more quickly than ever imagined. In a similar vein, the UN in Myanmar could have chosen to explicitly engage the international community in discussions about the underlying dilemma. This could, in turn, have fostered more nuanced thinking about the context of the conflict, and may have released some of the pressure to address human rights. Clearly identifying the major obstacle could further be used as an opportunity to clarify the mandate from UN headquarters and to contextualize international human rights standards into a Myanmarspecific, or even Buddhist, perspective.

Bypassing refers to a method that seeks a pragmatic substitute or provisional mechanism that satisfies the imperatives in some alternative way. These measures typically circumvent the problem or postpone the solution; consequently, they often confer some genuine functional or strategic advantage in order to compensate for the apparent political or ethical concession. In the Ukrainian case, bypassing could include choosing to ignore the absence of non-mainstream views in dialogues. Instead, other, tailor-made and low-threshold mechanisms of civic participation in communities could be developed that would include minority views. This could avoid further polarization between political affiliation groups and create an opportunity to show the Ukrainian people that civil society groups (which some consider to be puppets of the Russian government) are part of Ukrainian democratic structures that deserve their trust.

\section{Conclusion}

In sum, when facing intractable dilemmas and trade-offs, peacemakers do not necessarily need to capitulate if they dare to be creative. The framework presented in this article offers a practically applicable routine of systematic optional thinking for situations that otherwise could be considered unsolvable. By walking through different strategies for developing alternative responses, 
the model reduces and reorganizes the complexity of difficult decisions. It reveals both non-negotiable red lines and the unseen flexibilities of each case. Used effectively, the framework can help define and reveal contextsensitive and widely acceptable solutions. In the best case, the model can transform a lose-lose or win-lose into a win-win situation, and turns dilemma and tradeoff decision-making into something playful and constructive. In the worst case, a difficult decision might remain unresolved even after all strategies have been attempted. At a minimum, however, the framework provides a comprehensive and conscientious way to explain and justify a tough choice.

\section{Acknowledgments}

This research was supported by Viadrina B/ORDERS IN MOTION Seed Money.

\section{Conflict of Interests}

The authors declare no conflict of interests.

\section{References}

Acharya, A. (2004). How ideas spread: Whose norms matter? Norm localization and institutional change in Asian regionalism. International Organization, 58(2), 239-275.

Beardsley, K. (2011). The mediation dilemma. Ithaca, NY: Cornell University Press.

Borton, T. (1970). Reach, touch, and teach: Student concerns and process education. New York, NY: McGrawHill.

Bush, R. A. B. (1994). The dilemmas of mediation practice: A study of ethical dilemmas and policy implications. Journal of Dispute Resolution, 1994(1), 1-55.

Conciliation Resources. (2018). Accord issue 27: Incremental peace in Afghanistan. Reliefweb. Retrieved from https://reliefweb.int/report/afghanistan/ accord-issue-27-incremental-peace-afghanistan

Cooley, J. W. (2005). Creative problem solver's handbook for negotiators and mediators: A pracademic approach. Washington, DC: American Bar AssociationSection of Dispute Resolution.

Davis, L. (2014). EU foreign policy, transitional justice and mediation: Principle, policy and practice. London: Routledge.

de Coning, C. (2018). Adaptive peacebuilding. International Affairs, 94(2), 301-317.

Falcó-Gimeno, A. (2011). Decision-making in coalition governments: Compromise and compartmentalization nested in a prisoner's dilemma. SSRN Electronic Journal. http://dx.doi.org/10.2139/ssrn.2241114

Festinger, L. (2009). A theory of cognitive dissonance. Stanford, CA: Stanford University Press.

Frazer, O. (2015). International engagement on Buddhist-Muslim relations in Myanmar. The $R e$ - view of Faith \& International Affairs, 13(4), 82-86.

Gert, B. (2007). Common morality: Deciding what to do. Oxford: Oxford University Press.

Gigerenzer, G. (2008). Gut feelings: The intelligence of the unconscious. London: Penguin Books.

Goffman, E. (1986). Frame analysis: An essay on the organization of experience. Boston, MA: Northeastern University Press.

Gowans, C. W. (Ed.). (1987). Moral dilemmas. New York, NY: Oxford University Press.

Greig, J. M., \& Diehl, P. F. (2005). The peacekeepingpeacemaking dilemma. International Studies Quarterly, 49(4), 621-645.

Hammel, S. (2011). Handbuch der therapeutischen Utilisation: Vom Nutzen des Unnützen in Psychotherapie, Kinder- und Familientherapie, Heilkunde und Beratung [Handbook of therapeutic utilization: About the use of the useless in psychotherapy, child and family therapy, medical science and counseling]. Stuttgart: Klett-Cotta.

Harding, C. G. (2017). Moral dilemmas and ethical reasoning. London: Routledge.

Hayes, M. (2017). Incrementalism and public policymaking. In Oxford Research Encyclopedias. Retrieved from http://oxfordre.com/politics/view/10.1093/ acrefore/9780190228637.001.0001/acrefore9780190228637-e-133

Hayner, P. (2018). The peacemaker's paradox: Pursuing justice in the shadow of conflict. New York, NY: Routledge.

Hellmüller, S., Palmiano Federer, J., \& Pring, J. (2017). Are mediators norm entrepreneurs? Exploring the role of mediators in norm diffusion. Bern: Swisspeace.

Human Rights Council. (2018). Report of the detailed findings of the independent international fact-finding mission on Myanmar (A/HRC/39/CRP.2). Geneva: Human Rights Council. Retrieved from https:// www.ohchr.org/en/hrbodies/hrc/myanmarFFM/ Pages/ReportoftheMyanmarFFM.aspx

Kahneman, D. (2012). Thinking, fast and slow. London: Penguin Books.

Kirchhoff, L. (2009). Linking mediation and transitional justice: The use of interest-based mediation in processes of transition. In K. Ambos, J. Large, \& $\mathrm{M}$. Wierda (Eds.), Building a future on peace and justice (pp. 237-260). Berlin: Springer.

Kraus, A. I. (2011a). Culture-sensitive process design: Overcoming ethical and methodological dilemmas. Politorbis, 52(2), 35-48.

Kraus, A. I. (2011b). Interkulturelle Verfahrensethik: Ein Modell zur Vermittlung von Konflikten zwischen partikularen Verfahrensnormen [Intercultural procedural ethics: A model for mediating conflicts between procedural norms]. Stuttgart: Kohlhammer.

Kraus, A. I., \& Kyselova, T. (2018). Doing action research on dialogues in Ukraine. Zeitschrift Für Beratungs und Managementwissenschaften, 2018(4), 64-71.

Kyselova, T. (2018). Understanding dialogue: Survey- 
based study. Kyiv: Mediation and Dialogue Research Center.

Lakoff, G., \& Wehling, E. (2016). Your brain's politics: How the science of mind explains the political divide. Exeter: Imprint Academic.

Lanz, D. (2011). Who gets a seat at the table? A framework for understanding the dynamics of inclusion and exclusion in peace negotiations. International Negotiation, 16(2), 275-295.

Macfarlane, J. (2002). Mediating ethically: The limits of codes of conduct and the potential of a reflective practice model. Osgoode Hall Law Journal, 40(1), 42.

Margalit, A. (2010). On compromise and rotten compromises. Princeton, NJ: Princeton University Press.

Mason, S. (2016). Combining best, good, and emergent practice. Nadel Newsletter, 2016(1), 3-4.

McWilliams, N. (2011). Psychoanalytic diagnosis: Understanding personality structure in the clinical process. New York, NY: The Guilford Press.

Nathan, L. (2016). How and why African mediators compromise democracy. Paper presented at the Conference on the Ethics of Negotiation in Armed Conflicts, Pennsylvania, United States of America.

Paffenholz, T. (2014). Civil society and peace negotiations: Beyond the inclusion-exclusion dichotomy. $\mathrm{Ne}$ gotiation Journal, 30(1), 69-91.

Palmiano Federer, J. (2018). We do negotiate with terrorists: Navigating liberal and illiberal norms in peace mediation. Critical Studies on Terrorism, 12(1), 19-39.

Rogers, M. (2012). Contextualizing theories and practices of bricolage research. The Qualitative Report, 17(48), 1-17.

Safi, M. (2018, September 18). 'Tied to trees and raped': UN report details Rohingya horrors. The Guardian. Retrieved from https://www.theguardian.com/ world/2018/sep/18/tied-to-trees-and-raped-unreport-details-rohingya-horrors

Sasse, G., \& Lackner, A. (2018). War and identity: The case of the Donbas in Ukraine. Post-Soviet Affairs, 34(2/3), 139-157.

Schneider, S. L., \& Shanteau, J. (Eds.). (2003). Emerging perspectives on judgment and decision research. Cambridge: Cambridge University Press.

Schön, D. A. (1983). The reflective practitioner: How professionals think in action. New York, NY: Basic Books.

SCORE. (2016). Social cohesion and reconciliation index.
Executive brief on identity and emerging trends: Is Ukraine heading towards the West or Russia? Nicosia: SCORE. Retrieved from https://www.scoreforpeace. org/files/publication/pub_file//ukraine/FINAL\%20 ENG\%20-\%20SCORE\%20Ukraine\%20Policy\%20Brief \%20-\%20Identity\%20\&\%20Emerging\%20Trends.pdf

Shapira, O. (2018). A theory of mediators' ethics: Foundations, rationale, and application. Cambridge: Cambridge University Press.

Shapiro, D. (2017). Negotiating the nonnegotiable: How to resolve your most emotionally charged conflicts. New York, NY: Penguin Books.

Snowden, D. J., \& Boone, M. E. (2007). A leader's framework for decision making. Harvard Business Review, 85(11), 68-76.

Spangler, B. (2013). Win-win/win-lose/lose-lose situations. Beyond Intractability. Retrieved from https:// www.beyondintractability.org/essay/win-lose

Sparrer, I. (2007). Miracle, solution and system: Solutionfocused systemic structural constellations for therapy and organisational change. Cheltenham: Solutions Books.

Statman, D. (1995). Moral dilemmas. Amsterdam: Rodopi.

Svensson, I., \& Brounéus, K. (2013). Dialogue and interethnic trust: A randomized field trial of 'sustained dialogue' in Ethiopia. Journal of Peace Research, 50(5), 563-575.

UK Government Stabilization Unit. (2019). The UK governments approach to stabilisation: A guide for policy makers and practitioners. London: UK Government Stabilization Unit. Retrieved from https:// assets.publishing.service.gov.uk/government/ uploads/system/uploads/attachment_data/file/ 784001/The_UK_Government_s_Approach_to_ Stabilisation_A_guide_for_policy_makers_and_ practitioners.pdf

United Nations. (2006). United Nations juridical yearbook: 2006. New York, NY: United Nations.

Weiss, J. N. (2003). Trajectories toward peace: Mediator sequencing strategies in intractable communal conflicts. Negotiation Journal, 19(2), 109-115.

Weston, A. (2006). Creative problem-solving in ethics. New York, NY: Oxford University Press.

Zartman, I. W. (2008). Negotiation and conflict management: Essays on theory and practice. London: Routledge.

\section{About the Authors}

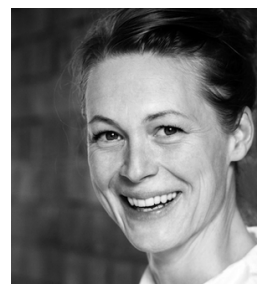

Anne Isabel Kraus (PhD), Conflict Researcher, Mediator, Supervisor/Coach, is Co-Director of the Center for Peace Mediation at European University Viadrina, Germany. Her current research focuses on dilemmas in peacemaking in various contexts, with a special focus on Ukraine, where she has also practically supported local dialogue actors. She teaches mediation and decision-making at various academic and policy institutions and provides conceptual support and supervision/coaching to peacemaking actors such as the German Federal Foreign Office, the GIZ and NGOS. 

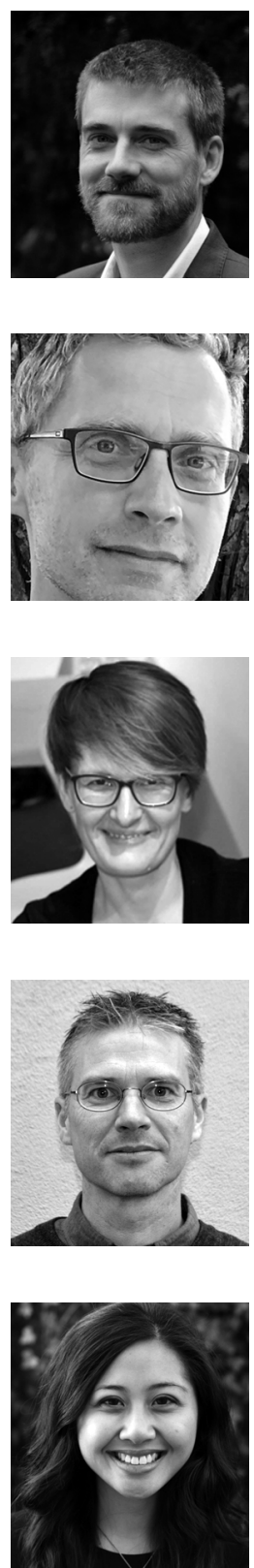

Owen Frazer is Senior Program Officer in the Mediation Support Team at the Center for Security Studies, ETH Zurich, Switzerland. Working within the program on Culture and Religion in Mediation (joint program with Swiss Federal Department of Foreign Affairs [FDFA]), he provides trainings to mediation practitioners and policy-makers, develops practice and policy guidance, and directly supports mediation and conflict transformation processes. Owen is also a Doctoral Researcher at the University of Birmingham, where he is investigating the role of mediation in overcoming impasses during formal peace negotiations.

Lars Kirchhoff (PhD), International Lawyer and Practicing Mediator, is Academic Director of the Institute for Conflict Management and Co-Director of the Center for Peace Mediation at European University Viadrina, Germany. He teaches mediation at institutions like the German Federal Foreign Office, the EU and the OSCE and a wide spectrum of organizations, foundations and think tanks. He coaches diplomats and special representatives to improve their mediation and process skills, advises on specific crisis regions, and serves as facilitator in conflict.

Tatiana Kyselova (PhD) is Associate Professor at the Departments of Law and Political Science of National University of Kyiv-Mohyla Academy, Ukraine. She is the Founder and Head of the Mediation and Dialogue Research Center at Kyiv-Mohyla Academy. She has doctoral degrees in Law and SocioLegal Studies from the University of Oxford and the Ukrainian Academy of Sciences. Her current research projects focus on the impact of dialogues and inclusiveness of peace processes in Ukraine and in other conflict contexts.

Simon J. A. Mason (PhD) is Senior Researcher and Head of the Mediation Support Team at the Center for Security Studies, ETH Zurich, Switzerland. Within the Mediation Support Project (joint program with Swisspeace, funded by the Swiss FDFA) and the Culture and Religion in Mediation program (joint program with Swiss FDFA), he trains actors from various conflict contexts and policy and academic institutions in conflict analysis, dialogue, negotiation, and mediation. He is a member of the UN and OSCE mediation rosters and a Senior Advisor in the MAS ETH Mediation in Peace Processes.

Julia Palmiano Federer (PhD) is a Program Officer in the mediation team at Swisspeace, Switzerland, and completed her PhD at the University of Basel. Her doctoral research analyses the role of NGO mediators in norm diffusion, specifically in the peace process in Myanmar. She has published academic articles and policy papers on Myanmar politics and diverse topics in mediation such as norms, gender, and counterterrorism. Furthermore, Julia works on Swisspeace's activities supporting national actors involved in Myanmar's peace process. 